\title{
Incentives and Government Relief for Risk
}

\section{Citation}

Louis Kaplow, Incentives and Government Relief for Risk, 4 J. Risk \& Uncertainty 167 (1991).

\section{Published Version}

http://www.springerlink.com/content/ju5q803440575362/

\section{Permanent link}

http://nrs.harvard.edu/urn-3:HUL.InstRepos:12207435

\section{Terms of Use}

This article was downloaded from Harvard University's DASH repository, and is made available under the terms and conditions applicable to Other Posted Material, as set forth at http:// nrs.harvard.edu/urn-3:HUL.InstRepos:dash.current.terms-of-use\#LAA

\section{Share Your Story}

The Harvard community has made this article openly available.

Please share how this access benefits you. Submit a story.

\section{Accessibility}


NBER WORKING PAPER SERIES

INCENTIVES AND GOVERNMENT RELIEF FOR RISK

Louis Kaplow

Working Paper No. 3007

NATIONAL BUREAU OF ECONOMIC RESEARCH

1050 Massachusetts Avenue

Cambridge, MA 02138

June 1989

Harvard University and National Bureau of Economic Research. I am grateful for comments from Lucian Bebchuck, Martin Feldstein, John Parsons, Michael Rothschild, Steven Shave11, and Lawrence Summers, and for support from the John M. Olin Foundation. This paper is part of NBER's research program in Taxation. Any opinions expressed are those of the author not those of the National Bureau of Economic Research. 
NBER Working Paper $\$ 3007$

June 1989

INCENTIVES AND GOVERNMENT RELIEF FOR RISK

\section{ABSTRACT}

Government relief is offered for a wide range of risks - - natural disaster, economic dislocation, sickness and injury. This paper explores the effect of such relief on incentives and the allocation of risk in a model with private insurance. It is shown that government relief is inefficient, even when its level is less than the private insurance coverage that individuals would otherwise have purchased and even when private insurance coverage is incomplete due to problems of moral hazard.

Louis Kaplow

Harvard Law School

Griswold Hall-Room 402

Harvard University

Gambridge, MA 02138 
A number of important risks - natural disaster, economic dislocation, sickness and injury - - sometimes give rise to government relief. ${ }^{1}$ This paper examines the effect of such relief on incentives and the allocation of risk in a model with private insurance. The primary conclusion is that government relief distorts individuals' incentives: Individuals' decisions take into account only their own exposure to loss - . the portion of loss uncompensated by goverment relief - - rather than the total loss. Moreover, given the availability of private insurance, the resulting loss from distorted incentives exceeds any benefit from relief in allocating risk.

The paper begins with the straightforward situation in which insurance companies can observe individuals' risk-reducing behavior. In this case, as is well recognized, insurance policies in which premiums are based on behavior allow individuals to achieve a first-best outcome (in which insurance against loss is complete and incentives are not distorted) without government relief. With relief, however, a first-best outcome is not achieved. Individuals purchase full insurance coverage against their exposure, so that relief and insurance completely compensate for any loss. But individuals are not induced to behave optimally. They are concerned only about how their behavior affects their insurance premiums, which, of course, are based on their exposure rather than total losses; as a result, the effect of risk-reducing behavior on the expected cost of government relief is ignored.

The paper then considers the situation in which insurance companies cannot observe individuals' risk-reducing behavior. In this case, which involves moral hazard, individuals generally purchase less than complete coverage against their exposure, in order to retain some incentive to reduce risk.

1 Relief, as distinguished from insurance, typically is not at a level chosen by individuals and does not entail charging individuals a premium that is a function of their observable behavior (including the level of insurance coverage they purchase). 
Here government relief distorts insurance decisions and thus behavior as weII: In determining the degree of residual risk to bear, individuals do not take into the account that their incentives to reduce risk affect the expected cost of government relief.

After demonstrating these results, I comment briefly on the range of situations to which they apply.

\section{The Model}

\section{A. Definitions and First-Best Outcome}

A standard model of the risk of 10 ss and insurance ${ }^{2}$ is considered in studying government relief. It is assumed that individuals choose an expenditure level $x$, which determines the probability $p(x)$ of a loss $\lambda$, where $\mathrm{P}^{\prime}<0$ and $\mathrm{P}^{\prime \prime}>0$. An individual's utility $U$ is a function of wealth, initially assumed to be zero, where $U^{\prime}>0$ and $U^{\prime \prime}<0 . U_{\lambda}$ and $U_{0}$ denote, respectively, utility evaluated in the states with and without the loss occurring. The government provides relief $r$ in the event of a loss; the program of relief is financed by a lump-sum tax $\tau=\mathrm{pr}$. An individual, knowing the government's relief policy, chooses a level of insurance coverage $q$, paid in the event of a loss, and is charged an actuarially fair premium $\pi=\mathrm{pq} \cdot{ }^{3}$ An individual's expected utility is therefore

$$
\text { (1) } \begin{aligned}
E U & =(1-p(x)) U(-x-\pi-r)+p(x) U(-x-\pi-\tau-\lambda+q+r) \\
& =(1-p(x)) U_{0}+p(x) U_{\lambda} .
\end{aligned}
$$

The first-best levels of $r, q$, and $x$ solve

2 See Arrow (1963), Holmström (1979), Shavell (1979).

3 It is assumed that insurance companies can observe individuals' aggregate purchases of insurance (and that they know the government's relief policy). See Arnott and Stiglitz (1987), Pauly (1974). 
(2) $\underset{r, r, q, \pi, x}{\operatorname{Max}}$ EU subject to:
(A) $\tau-\mathrm{pr}$
(B) $\pi=p q$.

Substituting $\mathrm{pr}$ for $\tau$ and $\mathrm{pq}$ for $\pi$ and differentiating ( 1 ), we have:

$$
\begin{aligned}
& \text { (3) } \frac{d E U}{d r}=\frac{d E U}{d q}=(1-p) U_{0}^{\prime} \cdot[-p]+p U_{\lambda}^{\prime} \cdot[-p+1]=0 \text {, or } \\
& \text { (4) } p(1-p)\left[U_{\lambda}^{\prime}-U_{0}^{\prime}\right]=0 \text {. }
\end{aligned}
$$

Wealth will thus be equal in the states with and without a loss, so that $q+r-\lambda$. Hence, $E U$ can be written simply as $U(-x-p(x) \lambda)$, so that the first-best $x$ must minimize $x+p(x) \lambda$, the sum of the costs of avoiding the loss and the expected loss. This implies that $x$ is determined by

(5) $P^{\prime}(x)=-\frac{1}{\lambda}$.

The next two sections consider optimal relief. The government's problem consists of choosing $r$ so as to maximize expected utility subject to the requirements that

- lump-sum taxes finance expected relief payments -- as in (2A) - - and

- the individual chooses a feasible insurance contract and expenditure level $x$ so as to maximize expected utility, where $r$ and $r$ are taken as given.

This problem is now analyzed explicitly in the two cases noted in the introduction.

\section{B. First-Best Insurance}

If insurance companies can observe expenditure levels $x$, they will be led to offer insurance policies that take individuals' behavior into account. In particular, assume that insurance companies charge a premium $\pi$ equal to $p(x) q .^{4}$ As a result, the optimization problem for the government in this case is

4 Alternative models would yield equivalent results. For example, individuals could choose $\pi$, while the insurance company would offer a schedule $q(x)$, where, for any $x, q(x)$ is the level of coverage for which $\pi-p(x) q(x)$. 
(6) $\underset{Y, T}{\operatorname{Max}}$ EU subject to:

(A) $r=\mathrm{pr}$

(B) $\left.\underset{q, \pi, x}{\operatorname{Max}} \mathrm{EU}\right|_{\mathrm{r}, \tau}$ subject to:

(i) $\pi(x)=p(x) q$.

The government's problem (6), unlike (2), involves an added constraint ( 8 ), corresponding to the condition that individuals' insurance coverage and expenditure decisions are privately optimal. Note that, at $r=0$, the private maximization in (B) is the same as that for the first best (2). ${ }^{5}$

More generally, for any $r$, the problem (B) is identical to that in (2) where one substitutes for the total loss $\lambda$ that portion to which the individual is exposed, $\lambda-r$ (and initial income is $-r$ ). As a result, the solution involves, from (4), equal wealth in the states with and without a loss $(q=\lambda-r)$ and an expenditure level that minimizes $x+p(x)(\lambda-r)$. Hence,

(7) $\mathrm{P}^{\prime}(\mathrm{x})=-\frac{1}{\lambda-\mathrm{r}}$.

It is clear (compare (5)) that the first-best level of $x$ will be chosen if and only if $r=0$. In addition, the higher is $r$, the lower is $x$ and the lower is expected utility. 6

PROPOSITION I: If the expenditure level $\mathrm{x}$ is observable by insurance companies, the first-best outcome is achieved with no relief, $r=0$. Moreover, $r=0$ is the unique optimum.

\section{Second-Best Insurance}

In many instances, $x$ will not be observable by insurance companies, so the optimal insurance contract in the absence of government relief will be second-

5 The first best required only that $q+r=\lambda$, so that $q$ and $r$ were redundant instruments in (2).

6 It can readily be demonstrated that sign dEU/dr $=-\operatorname{sign} r$, for $r<\lambda$. For $r \geq \lambda$, the lowest possible $x$ will be chosen; expected utility will be lower than for any $r<\lambda$. 
best due to moral hazard. In this case, the optimization problem for the government is

(8) Max EU subject to: $\mathrm{r}, \mathrm{T}$

(A) $\tau=\mathrm{pr}$

(B) $\left.\underset{q, \pi}{\operatorname{Max}}\right|_{r, T}$ subject to:

(i) $\pi=\mathrm{pq}$

(ii) $\left.\underset{\mathbf{x}}{\operatorname{Max}} \mathrm{EU}\right|_{\mathrm{r}, \tau, \mathrm{q}, \boldsymbol{\pi}}$.

(B) indicates that individuals purchase insurance to maximize expected utility (given $r$ and $r$ ). Constraint ( $i i$ ) indicates that insurance is determined (and the actuarially fair premium is set) taking into account that an individual will choose $x$ to maximize expected utility, with $q$ and $\pi$ taken as given (as well as $r$ and $r$ ).

This problem differs from that involving first-best insurance: The earlier problem (6), for constraint (B), involved the maximization of expected utility over $q, \pi$, and $x$ (given $r$ and $r$ ) subject to (i). Here ( 8 ), insurance is subject to the familiar moral hazard problem. Government relief will make matters worse, because individuals choose insurance coverage as if the loss were $\lambda$ - r rather than $\lambda$, which in turn affects their expenditure decision. Note that the government's problem ( 8 ), involving the choice of $r$, is the same as the individual's optimization problem (B) when $r=0$, involving the choice of $q$, except that the former problem has an added constraint. ${ }^{7}$ These observations suggest the following result.

LEMMA: For any level of relief $r$, let $q$ and $x$ be the insurance coverage and expenditure level that an individual would choose. Let $\hat{\mathbf{x}}$ be the expenditure level that would be chosen if $r=0$ and insurance coverage is $r+q$. Then $\left.E U\right|_{x, q, x}=\left.E U\right|_{0, r+q, \hat{x}}$, and $\mathrm{x}=\hat{\mathrm{x}}$; that is, the utility and expenditure level at any level of relief can be replicated with no relief and insurance coverage of $r+q$.

7 It should be clear that this reasoning is not dependent upon the particular model adopted here. 
PROOF: Let $\hat{\mathrm{I}}=0$ and $\hat{\mathrm{q}}=r+q$. Consider insurance premium $\hat{\pi}=\mathrm{p} \hat{\mathrm{q}}$. Noting that $\hat{r}=0($ since $\hat{\mathbf{r}}=0)$, one has:

(9) $\hat{\pi}+\hat{r}=p \hat{q}=p r+p q=\tau+\pi$.

It is therefore clear that the maximization decision involving $x$ ( $8 B i i)$ is the same for the original and transposed problem, so the same expenditure level will be chosen. ${ }^{8}$ This implies that the posited premium $\hat{\pi}$ satisfies ( $8 \mathrm{Bi}$ ). Thus, $\mathrm{x}=\hat{\mathrm{x}}$ and expected utility is the same for both problems, which completes the proof.

The lemma immediately implies that $r=0$ is an optimum, since the expected utility achievable at any $r \neq 0$ can also be achieved at $r=0$. In fact, $r=0$ is the unique optimum. To demonstrate this requires us to examine the firstorder conditions for $q(8 B)$ and $x$ ( $8 B i i)$. For the latter,

(10) $\frac{d E U}{d x}=-(1-p) U_{o}^{\prime}-p^{\prime} U_{0}-p_{\lambda}^{\prime}+p^{\prime} U_{\lambda}=0$, or

(11) $\mathrm{P}^{\prime}(\mathrm{x})=-\frac{\overline{\mathrm{U}}^{\prime}}{\mathrm{U}_{\mathrm{o}}-\mathrm{U}_{\lambda}}$,

where $\overline{\mathrm{U}}^{\prime}=(1-\mathrm{p}) \mathrm{U}_{0}^{\prime}+\mathrm{pU}_{\lambda}^{\prime}$. Compare this expression with (5) and (7). (Note that if individuals were risk-neutral, (11) would reduce to $\mathrm{P}^{\prime}=$ $-1 /(\lambda-I-q)$.) When choosing $x$, individuals consider only the portion of the loss that is not compensated by government relief or insurance.

For the maximizing insurance decision,

$$
\begin{aligned}
\frac{d E U}{d q}= & (1-p) U_{o}^{\prime} \cdot\left[-x_{q}-p-q p^{\prime} x_{q}\right]-p^{\prime} x_{q} U_{o}+p U_{\lambda}^{\prime} \cdot\left[-x_{q}-p-q p^{\prime} x_{q}+1\right] \\
& +p^{\prime} x_{q} U_{\lambda}=0
\end{aligned}
$$

where $x_{q}$ denotes the derivative of $x$ with respect to $q$. Because (10) holds at the optimum, ${ }^{9}$ many of the terms multiplying $x_{q}$ can be eliminated, and the

8 This result holds if the solution is unique. See note 9. For other cases, it would be sufficient to assume that, if multiple global optima for $x$ exist, the same selection rule is used in the initial and transposed problems.

9 As explored in Arnott and Stiglitz (1988) and Grossman and Hart (1983), for this substitution necessarily to be valid, the solution to (10) must be a 
remainder can be regrouped as follows:

(13) $\frac{d E U}{d q}=p(1-p)\left(U_{\lambda}^{\prime}-U_{0}^{\prime}\right)-p^{\prime} q x_{q^{\prime}} \bar{U}^{\prime}=0$

The first term reflects the benefit of further equalizing wealth between the states with and without a loss, and the second is the incentive cost (moral hazard). The critical feature for assessing the effect of government relief is that this latter term is weighted by $q$, not $q+r$ : Only that portion of the incentive cost covered by insurance is reflected in the insurance decision. The portion covered by government relief is ignored, just as in the case of first-best insurance.

To establish uniqueness, note that, at any optimum $r$, the first-order condition for $q$ (13) must hold not only for the stated $r$, but also, under the lemma, for the equivalent scheme in which $\hat{r}=0$. For the initial and transposed schemes, all variables in (13) have the same values, except (possibly) for $q$ and $x_{q}$. Therefore, $q x_{q}=\hat{q} \hat{x}_{q}$.

To evaluate $\mathrm{x}_{\mathrm{q}}$ and $\hat{\mathrm{x}}_{\mathrm{q}}$, differentiate the first-order condition for $\mathrm{x}(10)$ with respect to $q$ :

(14) $\frac{d^{2} E U}{d q d x}=-(1-p) U_{0}^{\prime \prime} \cdot\left[-x_{q}-p-q p^{\prime} x_{q}\right]+p^{\prime} x_{q} U_{0}^{\prime}-p^{\prime} U_{o}^{\prime} \cdot\left[-x_{q}-p-q p^{\prime} x_{q}\right]$

$$
\begin{aligned}
& -p^{\prime \prime} x_{q} U_{0}-p U_{\lambda}^{\prime \prime} \cdot\left[-x_{q}-p-q p^{\prime} x_{q}+1\right]-p^{\prime} x_{q} U_{\lambda}^{\prime} \\
& +p^{\prime} U_{\lambda}^{\prime} \cdot\left[-x_{q}-p-q p^{\prime} x_{q}+1\right]+p^{\prime \prime} x_{q} U_{\lambda}=0 .
\end{aligned}
$$

Grouping those texms that correspond to $U_{x x}$, the second derivative of expected utility with respect to $x,{ }^{10}$ and rearranging yields

$$
\begin{gathered}
x_{q}\left[U_{x x}-q p^{\prime}\left[p^{\prime}\left(U_{\lambda}^{\prime}-U_{o}^{\prime}\right)-\left((1-p) U_{o}^{\prime \prime}+p U_{\lambda}^{\prime \prime}\right)\right]\right]= \\
-p^{\prime}\left[p U_{o}^{\prime}+(1-p) U_{\lambda}^{\prime}\right]+p(1-p)\left[U_{\lambda}^{\prime \prime}-U_{o}^{\prime \prime}\right]
\end{gathered}
$$

unique maximum. For present purposes, it is assumed that $\mathrm{d}^{2} \mathrm{EU} / \mathrm{dx}^{2}<0$ where relevant.

10

$$
\frac{d^{2} E U}{d x^{2}}=(1-p) U_{0}^{\prime \prime}+p U_{\lambda}^{\prime \prime}+2 p^{\prime}\left(U_{0}^{\prime}-U_{\lambda}^{\prime}\right)+p^{\prime \prime}\left(U_{\lambda}-U_{0}\right) .
$$


It simplifies to rewrite this expression as

(16) $x_{q}\left(U_{x x}-q \theta\right)=\Omega$

For the substitutions made, note that $\theta$ and $\Omega$, as well as $U_{x x}$ will have the same values for the initial and transposed schemes, given the results of the lemma. Thus, we can equate

(17) $x_{q}\left(U_{x x}-q \theta\right)=\hat{x}_{q}\left(U_{x x}-\hat{q} \theta\right)$, or

(18) $\mathrm{qx}_{\mathrm{q}}\left(\mathrm{U}_{\mathrm{xx}} / \mathrm{q}-\theta\right)=\hat{\mathrm{q}} \hat{\mathrm{x}}_{\mathrm{q}}\left(\mathrm{U}_{\mathrm{xx}} / \hat{\mathrm{q}}-\theta\right)$.

Since $q x_{q}=\hat{q} \hat{x}_{q}, q=\hat{q} \cdot{ }^{11}$ This implies $r=0$.

PROPOSITION II: No relief, $r=0$, is the unique optimum, even when the expenditure level $\mathrm{x}$ is not observable by insurance companies.

The lemma indicates that insurance can mimic any level of government relief. Clearly, the government cannot improve upon $r=0 .{ }^{12}$ Uniqueness is illuminated by considering how individuals will choose $q$ when $r \in(0, \lambda)$. First, if $r>q^{*}$, where $q^{*}$ is the optimal level of insurance when $r=0$, individuals will purchase additional coverage despite the fact that the government offers relief above the level of coverage they would otherwise have purchased: At $q=0$, marginally increasing $q$ reduces risk-bearing costs and imposes no private incentive costs. (In (13), the first term is positive and the second is zero.) Second, even if $r \leq q^{*}$, one would expect individuals to purchase coverage such that $q+r>q^{*}$ : A marginal increase in total coverage from $q^{*}$ will produce the same risk-spreading benefits as in the case in which $r=0$, but less incentive cost (since a portion of the incentive cost is borne by the government). ${ }^{13}$

11 The only possible exceptions are: (1) $U_{x x}=0$; see note 9 . (2) $q x_{q}=0$; this implies equal wealth across states, which in turn implies (from 10) that $\mathrm{U}^{\prime}=0$, which is ruled out by assumption. (3) $\mathrm{qx}_{\mathrm{q}}$ and $\hat{\mathrm{q}} \hat{\mathrm{x}}_{\mathrm{q}}$ are both infinite; this will not hold at an optimum and would, in any event, from (16), imply that $U_{x x}-q \theta-0$ and $U_{x x}-\hat{q} \theta=0$, which is only possible if, again, $q-\hat{q}$ or if $\theta=0$ and $U_{x x}=0$, the latter having been considered.

12 In the absence of an externality, this result should not be surprising. The conclusion does not rule out all government action, such as taxes and subsidies applied to the relevant activities. See Arnott and Stiglitz (1986). 


\section{Concluding Remarks}

Goverment relief for risk distorts incentives because individuals no longer bear the full cost of their actions. Such relief is inefficient even when insurance coverage is incomplete due to moral hazard. These results are relevant to a wide range of govermment programs - including disaster relief, Medicare, trade adjustment assistance, and bailouts - and, as now noted, to windfall taxation and relief for changes in government policy as well.

(a) The model considered goverment relief for the risk of losses, but the analysis is equally applicable to the symmetric case involving windfall taxation of gains. Gains and losses are defined, after all, relative to an arbitrary origin. (Suppose in the model that $\lambda, q$, and $r$ are negative, where $\mathrm{p}^{\prime}>0$ and $\mathrm{p}^{\prime \prime}<0_{\text {, }}$ ) This application is consistent with the familiar notion that windfall taxation of gains distorts incentives to generate the gains.

(b) An important source of risk is that associated with government action itself - that is, with the enactment, repeal, or modification of regulations, tax rules, budget priorities, and so forth. The analysis presented here is applicable to government-created risk, suggesting (other things equal) the inefficiency of the wide range of mechanisms - - including compensation and windfall taxation, grandfathering, phased-in implementation -. often employed to mitigate gains and losses for those who invested under the preexisting regime. ${ }^{14}$

(c) If insurance markets suffer from imperfections other than moral hazard, government relief may be efficient. One problem of particular interest in this context is that some individuals may incorrectly perceive the

13 This final argument holds only locally. Subtle wealth effects must be ruled out to establish the result globally. Compare Kaplow (1987).

14 In this context, it would often be relevant to consider a model in which $p$ is given and the loss $\lambda$ is a function of individual decisions $x$, because individuals will often have little influence over the probability of government action whereas the amount of loss will be determined by their level of investment. (In such instances, the plausibility of first-best insurance may be greater than otherwise because the relevant states often will be observable.) For a model of this case and further consideration of issues arising in this context, including the effect of relief on the government's incentives, see Kaplow $(1986,1987)$. 
probability of loss. ${ }^{15}$ If the probability is underestimated significantly, govermment relief may have less of an adverse effect on incentives while spreading risk for which individuals would not choose to purchase insurance. Compulsory government insurance, however, would be more efficient than relief: For example, one who contemplated construction on a flood plain and underestimated the risk of a flood would be led to make a more efficient decision if notified in advance of the compulsory premium that would be charged for different levels of investment in different locations. Observe that government insurance (optional or compulsory) that imposes an actuarially fair premium taking into account other insurance coverage or that prohibits supplementary coverage has wholly different effects from those of government relief.

15 of course, other factors, such as adverse selection or administrative costs, can also provide a case for government insurance or relief. Note that diversification of ownership through financial markets may address these problems in some instances. Moreover, as to unsystematic risk, a diversified firm may effectively be risk-neutral, making all the more apparent the inefficiency of government relief. (The government generally is in no better position to absorb risk than are financial markets. See the discussion in Kaplow (1987) of the applicability of the Arrow and Lind (1970) result in this context.) 


\section{References}

Arnott, Richard, and Stiglitz, Joseph E. "Moral Hazard and Optimal Commodity Taxation." J. Pub. Econ. 29 (February 1986): 1-24.

. "Equilibrium in Competitive Insurance Markets with Moral Hazard." Princeton University Program for the Study of Economic Organization and Public Policy Discussion Paper No, 4, 1987.

$2484,1988$.

"The Basic Analytics of Moral Hazard," NBER Working Paper No.

Arrow, Kenneth J. "Uncertainty and the Welfare Economics of Medical Care." A.E.R. 53 (December 1963): $941-974$.

and Lind, Robert $C$. "Uncertainty and the Evaluation of Public

Investment Decisions." A.E.R. 60 (June 1970): 364-378.

Grossman, Sanford J., and Hart, Oliver D. "An Analysis of the Principal-Agent Problem." Econometrica 51 (January 1983): 7-45.

Holmström, Bengt. "Moral Hazard and Observability." Bell J. Econ. I0 (Spring 1979): $74-91$.

Kaplow, Louis. "An Economic Analysis of Legal Transitions." Harvard Law Rev. 99 (January 1986): 509-617.

- Optimal Transition Policy: Replacing Horizontal Equity with an Ex Ante Incentives Perspective. Unpublished doctoral dissertation, Harvard University, 1987.

Pauly, Mark. "Overinsurance and Public Provision of Insurance: The Roles of Moral Hazard and Adverse Selection." Q.J.E. 88 (February 1974): 44-62.

Shave11, Steven. "On Moral Hazard and Insurance." Q.J.E. 93 (November 1979): $541-562$. 